\title{
Heat Tolerance of Durum Wheat (Tritcum durum Desf.) Elite Germplasm Tested along the Senegal River
}

\author{
Amadou T. Sall ${ }^{1,2,3}$, Madiama Cisse ${ }^{4}$, Habibou Gueye ${ }^{5}$, Hafssa Kabbaj ${ }^{2,3}$, Ibrahima Ndoye ${ }^{1}$, \\ Abdelkarim Filali-Maltouf $^{2}$, Bouchra Belkadi ${ }^{2}$, Mohamed El-Mourid $^{3}$, Rodomiro Ortiz ${ }^{6}$ \& Filippo M. Bassi ${ }^{3}$ \\ ${ }^{1}$ University Cheikh Anta Diop, Dakar, Senegal \\ ${ }^{2}$ University Mohammed V, Rabat, Morocco \\ ${ }^{3}$ International Center for the Agricultural Research in the Dry Areas (ICARDA), Rabat, Morocco \\ ${ }^{4}$ Senegalese Institute for Agricultural Research (ISRA), Saint-Louis, Senegal \\ ${ }^{5}$ National Center for the Agricultural Research and development (CNRADA), Kaedi, Mauritania \\ ${ }^{6}$ Department of Plant Breeding (VF) Alnarp, Swedish University of Agricultural Sciences (SLU), Sweden \\ Correspondence: Filippo M. Bassi, International Center for the Agricultural Research in the Dry Areas (ICARDA), \\ Rabat, Morocco. Tel: 212-614-402-717. E-mail: f.bassi@cgiar.org
}

$\begin{array}{lcc}\text { Received: October 22, } 2017 & \text { Accepted: December 8, } 2017 & \text { Online Published: January 15, } 2018 \\ \text { doi:10.5539/jas.v10n2p217 } & \text { URL: https://doi.org/10.5539/jas.v10n2p217 }\end{array}$

The research is financed by Swedish Research Council (Vetenskapsradet) U-Forsk2013, "Deployment of molecular durum breeding to the Senegal Basin: capacity building to face global warming”.

\begin{abstract}
The Senegal River basin (Guinea, Mali, Mauritania, and Senegal) is a key agricultural production area in sub-Saharan Africa. Here, rice fields are left fallow during the cooler winter season, when the night temperatures reach $16{ }^{\circ} \mathrm{C}$ but the maximum daily temperatures remain above $30{ }^{\circ} \mathrm{C}$. This season was used for the first time to conduct multi-environmental trials of durum wheat. Twenty-four elite breeding lines and cultivars were tested for adaptation during seasons 2014-15 and 2015-16 at two stations: Kaedi, Mauritania and Fanaye, Senegal. Phenological traits, grain yield and its components were recorded. Top grain yield was recorded at 5,330 kg ha and the average yield at $2,484 \mathrm{~kg} \mathrm{ha}^{-1}$. The season lasted just 90 days from sowing to harvest. Dissection of the yield in its components revealed that biomass and spike fertility (i.e. number of seeds produced per spike) were the most critical traits for adaptation to these warm conditions. This second trait was confirmed in a validation experiment conducted in 2016-17 at the same two sites. Genotype $\times$ environment interaction was dissected by AMMI model, and the derived IPC values used to derive an 'AMMI wide adaptation index' (AWAI) to asses yield stability. The use of a selection index that combined adjusted means of yield and AWAI identified three genotypes as the most stable and high yielding: 'Bani Suef 5', 'DAWRyT118', and 'DAWRyT123'. The last two genotypes were also confirmed among the best in a validation trial conducted in season 2016-17. The data presented here are meant to introduce to the breeding community the use of these two research stations along the Senegal River for assessing heat tolerance of wheat or other winter cereals, as well as presenting two new ideal germplasm sources for heat tolerance, and the identification of spike fertility as the key trait controlling adaptation to heat stress.
\end{abstract}

Keywords: AMMI, genotype $\times$ environment interaction, selection index, short season, durum breeding, Mauritania

\section{Introduction}

The area along the Senegal River represents a major agricultural basin in Sub-Saharan Africa with the potential of 375,000 ha of arable and irrigated land. Today, a portion corresponding to approximately 200,000 ha is intensively cultivated with double seasons of rice (FAO, 2016). However, the cool season between middle of November to early March is not suitable for rice cultivation, and fields are mostly left at fallow. Preliminary results show that heat tolerant varieties of wheat could be cultivated in this area instead of the fallow season (Bado et al., 2010). 
Here is presented an attempt to investigate further the suitability of durum wheat production as a replacement for the fallow season by means of full scale breeding trials conducted over locations and years. The adaptability of a variety over a diverse environment is usually tested by the degree of its interaction with it (Ashraf et al., 2001). The importance of genotype $\times$ environment $(\mathrm{G} \times \mathrm{E})$ interactions in breeding programs has been demonstrated in many major crops, including wheat (Najafian et al., 2010; Zali et al., 2011). This interaction complicates the identification of superior genotypes for a range of environments and calls for the evaluation in multiple sites to determine their true genetic potential (Yaghotipour \& Farshadfar, 2007). Various statistical methods have been proposed to study G×E interactions (Lin et al., 1986; Becker \& Léon, 1988; Crossa, 1990; Lin \& Binns, 1994; Mohammadi \& Amri, 2008; Malosetti et al., 2013). The additive main effect and multiplicative interaction (AMMI) model was developed specifically for analysis of $\mathrm{G} \times \mathrm{E}$ interaction in multi-locations varietal trials (Zobel et al., 1988). It estimates the total $\mathrm{G} \times \mathrm{E}$ effect of each genotype and partitions it into interaction effects with environmental components (Malosetti et al., 2013).

Hence, the aim of this research was to identify stable and high yielding durum wheat genotypes well adapted to the Senegal River Basin through multi-year and multi-location trials, as well as pinpointing the main traits critical for adaptation to heat stress. To the best of our knowledge, this is the first time that such an effort is conducted for this region.

\section{Materials and Methods}

\subsection{Argo-Environmental Conditions}

The experiments were carried out in two irrigated Savanah-type experimental stations: Fanaye, Senegal (FAN: $16^{\circ} 53^{\prime} \mathrm{N} ; 15^{\circ} 53^{\prime} \mathrm{W}$ ) and Kaedi, Mauritania (KED: $16^{\circ} 14^{\prime} \mathrm{N}$; $13^{\circ} 46^{\prime} \mathrm{W}$ ) during winter seasons 2014-15, 2015-16 and 2016-17. FAN is located $150 \mathrm{Km}$ inland from the Senegal River delta, while KED is $300 \mathrm{~km}$ further away from the coast and its mitigating effect, and therefore tends to be warmer (Figure 1). FAN has sandy-clay soil with higher organic matter and good water holding capacity, while KED has lighter sandy-loam-clay soils with intermediate water holding capacity. All soils are rich in phosphorus (P) and low in the other nutrient, as typical for the 'Sahara effect' (Boy et al., 2008).

\subsection{Plant Materials and Experimental Design}

Twenty-one durum wheat elites were selected from two ICARDA international nurseries, the $1^{\text {st }}$ Afrique du Nord trials (AfN) and the $38^{\text {th }}$ International Durum Yield Trials (IDYT38), and from CIMMYT $46^{\text {th }}$ International Durum Yield Nurseries (IDYN46). In addition, the three cultivars 'Waha' (syn. 'Cham1', Syria and Algeria), 'Bani Suef5' (Egypt), and 'Miki3' (syn. 'Berdawni', Lebanon) were included as checks, thereby having 24 genotypes include in the 'discovery' trial conducted in seasons 2014-15 and 2015-16 (Table 1). 
Table 1. Durum wheat genotypes used for field evaluation, their best linear unbiased estimator (BLUE) for grain yield (GY) across two sites in two seasons along the Senegal River and its summary statistics

\begin{tabular}{|c|c|c|c|}
\hline \multirow{2}{*}{$\frac{\text { Genotype }}{\text { Icamoram7 }}$} & \multirow{2}{*}{$\begin{array}{l}\text { Pedigree } \\
\text { IcamorTritArarat0472/Ammar7 }\end{array}$} & \multicolumn{2}{|c|}{ GY $\left(\mathrm{kg} \mathrm{ha}^{-1}\right)$} \\
\hline & & 2,931 & a \\
\hline Margherita & Terbol97-5/Geruftel2 & 2,861 & $\mathrm{ab}$ \\
\hline Bani Suef 5 & Dupperez/Bushen3 & 2,858 & $\mathrm{ab}$ \\
\hline DAWRyT118 & Mrb5/TdicoAlpCol//Cham1 & 2,825 & $a b c$ \\
\hline Icavert & Ter1/3/Stj3//Bcr/Lks4/4/Aghrass1/3/Mrf1// Mrb16/ Ru & 2,762 & abcd \\
\hline DAWRyT123 & Mrb5/TdicoAlpCol//Cham1 & 2,730 & abcd \\
\hline DurAM-196 & Korifla/AegSpeltoidesSyr//Loukos & 2,683 & bcd \\
\hline DWAyT217 & Korifla/AegSpeltoidesSyr//Loukos & 2,645 & bcde \\
\hline IDYN46-748 & MXI12-13/C46IDYN/180129 & 2,639 & bcdef \\
\hline Icakassem1 & Geromtel1/Icasyr1 & 2,604 & cdefg \\
\hline DAWRyT317 & Korifla/AegSpeltoidesSyr//Mrb5 & 2,599 & cdefg \\
\hline Ouassara3 & Ouasloukos1/5/Azn1/4/BEZAIZSHF//SD19539/Waha/3/Gdr2 & 2,595 & cdefg \\
\hline Icaverve & Azeghar1/4/IcamorTA0462/3/Maamouri3 & 2,524 & defgh \\
\hline Waha & $\mathrm{Plc} /$ Ruff//Gta/Rtte & 2,438 & efghi \\
\hline Icarukus & Maamouri1/5/IcamorTA0462/4/Stj3//Bcr/Lks4/3/Icamor/6/Mgn13/Ainzen1 & 2,404 & fghi \\
\hline DAWRyT208 & Korifla/AegSpeltoidesSyr/Amedakul & 2,378 & ghi \\
\hline DWAyT306 & Korifla/AegSpeltoidesSyr//Heider & 2,345 & hi \\
\hline IDYN46-742 & MXI12-13/C46IDYN/180112 & 2,309 & hij \\
\hline Ouassara1 & Ouasloukos1/5/Azn1/4/BEZAIZSHF//SD19539/Waha/3/Gdr2 & 2,304 & hij \\
\hline IDYN46-707 & MXI12-13/C46IDYN/180006 & 2,250 & $\mathrm{ijk}$ \\
\hline DAWRyT110 & Amedakul1/TdicoSyrCol//Cham1 & 2,094 & $\mathrm{jk}$ \\
\hline DAWRyT104 & Amedakul1/TdicoJorCol//Cham1 & 2,028 & $\mathrm{kl}$ \\
\hline Bezaghras & Oss11/Stj5/5/Bicrederaa1/4/BEZAIZSHF// SD19539/Waha/3/Stj/Mrb3/6/Mgnl3/Aghrass2 & 2,018 & $\mathrm{kl}$ \\
\hline Miki3 & $\mathrm{Stj} 3 / / \mathrm{Bcr} / \mathrm{Lks} 4$ & 1,797 & 1 \\
\hline \multicolumn{2}{|l|}{ Mean } & \multicolumn{2}{|l|}{2,484} \\
\hline \multicolumn{2}{|l|}{ LSD } & \multicolumn{2}{|l|}{239} \\
\hline \multicolumn{2}{|c|}{ Coefficient of variation $(\%)$} & \multicolumn{2}{|l|}{9.6} \\
\hline \multicolumn{2}{|l|}{ Heritability } & \multicolumn{2}{|l|}{0.77} \\
\hline
\end{tabular}

A second set of genotypes identified as 'validation' experiment was conducted only in season 2016-17. It included twenty durum wheat elites selected from the $39^{\text {th }}$ International Durum Observation Nurseries (IDON39), the three best (DAWRyT123, DAWRyT118, Bani Suef 5) and the one earliest (Oussara3) genotypes from the two previous seasons used as checks (Table B1).

All experiments were performed in alpha lattice design with six sub-blocks of size four repeated two times. The genotypes were grown in experimental plots of $7.5 \mathrm{~m}^{2}$ at a sowing density of $120 \mathrm{~kg} \mathrm{ha}^{-1}$. A total of $150 \mathrm{~kg}$ of nitrogen were provided in three equal split applications, while $50 \mathrm{~kg}$ of phosphorus and potassium were provided as base fertilization before planting.

Weeds were chemically controlled during season 2014-15 by using a tank mixture of Derby (DowAgroscience, florasulam and flumetsulam) and Cossack (Bayer, sulfonylurea and safener) applied at Zadoks stage 14 (Z14, Zadoks et al., 1974), followed by a tank mixture of Derby and Pallas (DowAgroscience, pyroxsulam) at tillering stage (Z23). Mechanical weeding was also conducted as needed to ensure clean paddocks. For seasons 2015-16 and 2016-17 only mechanical weeding was conducted due to the unavailability of the chemical herbicides.

During 2014-15 season nine gravity irrigations were performed at intervals of 7-10 days in KED and in FAN for a total estimated of $320 \mathrm{~mm}$ and $410 \mathrm{~mm}$ of water provided, respectively. During 2015-16 season, the same number of gravity irrigations were performed in FAN, but reducing the quantity of water to approximately 360 $\mathrm{mm}$ total, while the number of irrigation was increased to 13 in KED for a total of approx. $380 \mathrm{~mm}$ of water. For season 2016-17 a total of approx. $380 \mathrm{~mm}$ of water were provided at the two stations via at intervals of 7-10 days.

\subsection{Data Recording}

The days to heading $(\mathrm{DtH})$ was recorded as the number of days elapsed from sowing to the moment that $50 \%$ of the plot showed spikes emerging from the flag leaf (Z59). Before maturity (Z83-87), the number of fertile spike 
per meter square $\left(\mathrm{Spk} / \mathrm{m}^{2}\right)$ were counted. Days to maturity (DtM) was recorded when $50 \%$ of the spikes turned yellow (Z91-92). A proxy of grain filling period (GFP) was then computed as the difference between DtM and DtH. Plant height (PLH) was measured in $\mathrm{cm}$ from the ground to the top of a representative ear excluding its awns. For each plot, only the middle rows were harvested for a total surface of $4.5 \mathrm{~m}^{2}$, dried and the biomass (Biom) weighted before threshing. The weight of the threshed grains was converted into yield (GY) expressed as $\mathrm{kg} \mathrm{ha}^{-1}$. The ratio between GY and Biom was expressed as harvest index (HI). One thousand grains were weighted in grams as 1000-kernels weight (TKW). The number of grain per meter square $\left(\mathrm{Gr} / \mathrm{m}^{2}\right)$ was imputed using the weight of the grains harvested from $4.5 \mathrm{~m}^{2}$ area and the average weight of one kernel derived from the TKW value, as per:

$$
G r / \mathrm{m}^{2}=\frac{\text { Harvested weight of plot }}{4.5 \mathrm{~m}^{2} \times \frac{\text { TKW }}{1000}}
$$

The number of grains per spike (Gr/spk) was derived from dividing the imputed number of grains per unit area by the number of spikes recorded for the same area, as follows:

$$
G r / s p k=\frac{G r / \mathrm{m}^{2}}{S p k / \mathrm{m}^{2}}
$$

DtM, GFP, and Spike/ $\mathrm{m}^{2}$ were not recorded for season 2014-15.

\subsection{Data Analysis}

Both genotypes and environments were considered as fixed effects. Best linear unbiased estimators (BLUEs) of all traits were obtained using META-R (Multi Environment Trial Analysis with R for Windows) version 5.0 (Alvarado et al., 2015). Analysis of variance was computed for each environment using $\mathrm{R}$ version 3.2.1 (R Core Team, 2015), while combined ANOVA was obtained with GEA-R (Genotype $\times$ Environment Analysis with R for Windows) version 2.0 (Pacheco et al., 2015). Heritability was calculated based on the modified method suggested by Burton and Devane (1953) as follows:

$$
H^{2}=\frac{\sigma^{2} g}{\sigma^{2} p}=\frac{\frac{M S_{g}-M S_{e}}{r}}{M S_{e}+\frac{M S_{g}-M S_{e}}{r}+\frac{M S_{g x e}-M S_{e}}{r \cdot e}}
$$

Where, $\sigma^{2} g$ is genotypic variance, $\sigma^{2} p$ is phenotypic variance, $M S g$ is the mean square for the genotype, $M S e$ is error mean square, $M S G \times E$ is the mean square of the interaction, $r$ is the number of replicates and $e$ is the number of environments considered.

The ratio of variance accounted by each source of variations $(G, E$, and $G \times E)$ was calculated dividing the sum of square of each for the total sum of square of the experiment.

For grain yield, $\mathrm{G} \times \mathrm{E}$ was partitioned by additive main effects and multiplicative interaction 2 (AMMI) model using R software (version 3.2.4) on R Studio. The 'AMMI wide adaptation index' (AWAI) was calculated using the following formula:

$$
A W A I=\Sigma_{i} s_{i} \cdot P C_{i} \mid
$$

Where, $i$ is the number of significant IPCs determined by classical Gollob F-test in R Studio corresponding to 4 IPC in this specific case, $\mathrm{si}$ is the percentage of total $\mathrm{G} \times \mathrm{E}$ variance explained by each IPC, and PC is the actual IPC value. AWAI values close to ' 0 ' are obtained for the most widely adapted and stable germplasm (Bassi \& Sanchez-Garcia, 2017). A performance index was generated by simultaneously selecting the best one third of the genotypes based on stability (AWAI) and one third best for average yield (BLUE). Genotypes that met both criteria were selected as the most suitable for cultivation along the Senegal River.

\section{Results}

\subsection{Heat-Prone Field Stations along the Senegal River}

Temperatures along the Senegal valley varied across sites and years with much warmer temperatures during the season 2015-16 (Figure 1) mainly at the flowering windows. Planting was completed on the $6^{\text {th }}$ of December in FAN15, then the $17^{\text {th }}$ of December in FAN16, and further delayed to the $24^{\text {th }}$ December in FAN17. Sowing occurred on the $3^{\text {rd }}$ December in KED15, $10^{\text {th }}$ December in KED16, and $18^{\text {th }}$ December in KED17. The delay of sowing at both sites were due to late harvesting of rather long rice seasons.

During all growing seasons in FAN, average minimum night temperatures oscillated between $14{ }^{\circ} \mathrm{C}$ and $18{ }^{\circ} \mathrm{C}$, while in KED the minimum night temperatures rarely descended below $22{ }^{\circ} \mathrm{C}$. Maximum day temperatures oscillated between $30^{\circ} \mathrm{C}$ and $33^{\circ} \mathrm{C}$ in FAN15, while reached between $34^{\circ} \mathrm{C}$ and $37{ }^{\circ} \mathrm{C}$ in FAN16 and FAN17. In KED16 the maximum temperatures remained constant between $33^{\circ} \mathrm{C}$ and $35^{\circ} \mathrm{C}$ while reached $37^{\circ} \mathrm{C}$ during the 
period of grain filling in KED17. Temperature data for KED15 could not be recorded due to the unavailability of a weather station at the time.

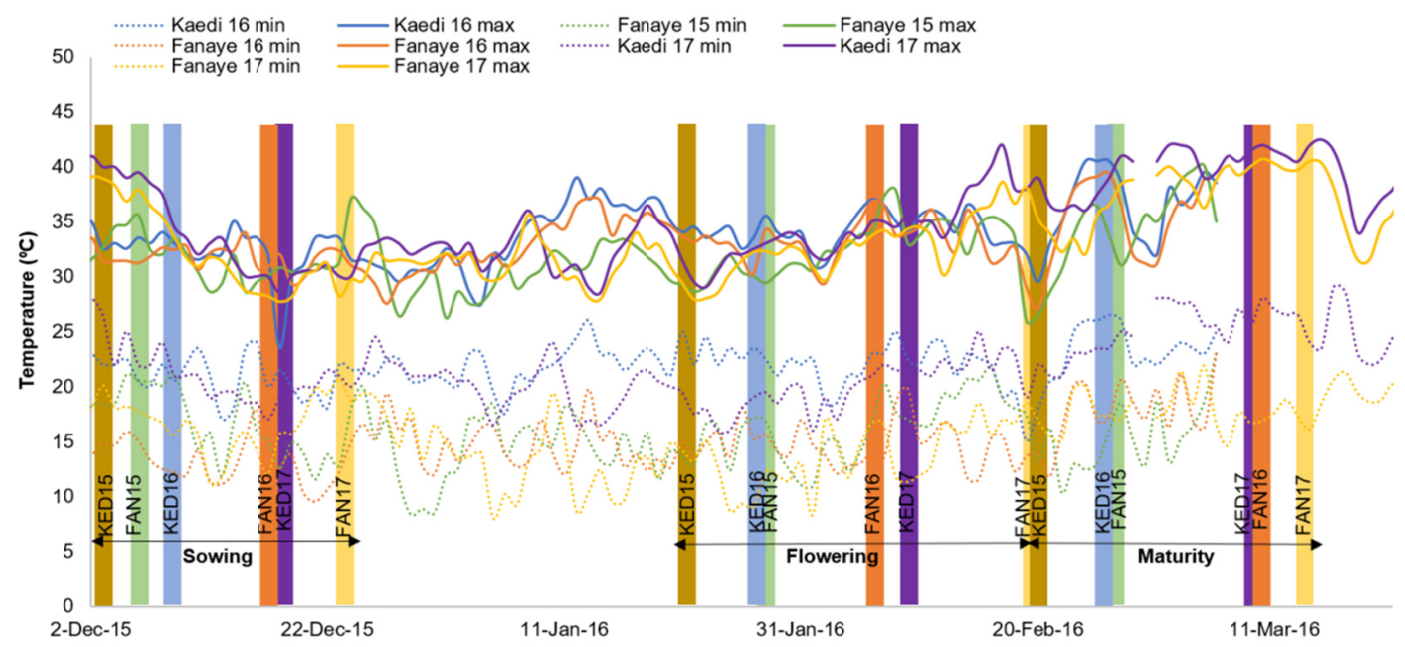

Figure 1. Maximum and minimum temperatures during seasons 2014-15, 2015-16 and 2016-17 at Fanaye and Kaedi with indications on the date of planting, average flowering and average maturity dates. Temperature data for Kaedi 2014-15 are not available

\subsection{Effect of Phenology}

The ANOVA (Table 2, Table A1 and Table A2) for DtH and PLH revealed statistically significant differences ( $p$ $<0.01)$ for the environments $(\mathrm{E})$, genotypes $(\mathrm{G})$, and their interaction $(\mathrm{G} \times \mathrm{E})$. The DtH mean across 4 environments of the two first seasons was 52 days with experimental coefficient of variation (CV) acceptably low (2.0\%). The 'validation' experiment of 2016-2017 for two environments had a DtH mean of 56 days with a $\mathrm{CV}$ of $1.6 \%$. The E explained $33.7 \%$ of the total variation in heading across the four environments, while $\mathrm{G}$ accounted for the largest part $(35.8 \%)$, and $\mathrm{G} \times \mathrm{E}$ for $20.0 \%$. The broad sense heritability $\left(\mathrm{H}^{2}\right)$ was measured at 0.85 (Table 2). PLH mean across environments was $72 \mathrm{~cm}$ and its CV $4.0 \%$. E explained $41.0 \%$ of the variance, $\mathrm{G}$ and $\mathrm{G} \times \mathrm{E}$ accounted for $30.1 \%$ and $20.7 \%$, respectively, with a broad sense heritability of 0.84 . The ANOVA (Table 3 and Table A7) for DtM revealed statistically significant differences $(p<0.05$ at FAN16 and $p<0.01$ at KED16, FAN17 and KED17) for the genotype effect (G). The overall DtM across the two environments (FAN16 and KED16) was 80 days with a CV of $1.1 \%$ while it was 86 days for the validation set with a $\mathrm{CV}$ of $1.3 \%$.

Table 2. Combined analysis of variance for days to heading (DtH), plant height (PLH), grain yield (GY), 1,000-kernels weight (TKW), harvest index (HI) and biomass (Biom) expressed as ratio of the total variance (\% var.), significance $(p)$, and broad sense heritability $\left(\mathrm{H}^{2}\right)$ across two sites in two seasons along the Senegal River

\begin{tabular}{|c|c|c|c|c|c|c|c|c|c|c|c|c|c|}
\hline \multirow{2}{*}{ SOV } & \multirow{2}{*}{$\mathrm{df}$} & \multicolumn{2}{|c|}{ DTH } & \multicolumn{2}{|c|}{ PLH } & \multicolumn{2}{|c|}{ GY } & \multicolumn{2}{|c|}{ TKW } & \multicolumn{2}{|c|}{$\mathrm{HI}$} & \multicolumn{2}{|c|}{ Biom } \\
\hline & & $p$ & $\%$ var. & $p$ & $\%$ var. & $p$ & $\%$ var. & $p$ & $\%$ var. & $p$ & $\%$ var. & $p$ & $\%$ var. \\
\hline $\mathrm{E}$ & 3 & $(0.001)$ & 33.70 & $(0.001)$ & 41.00 & $(0.001)$ & 77.70 & $(0.001)$ & 57.77 & $(0.001)$ & 66.39 & $(0.001)$ & 59.11 \\
\hline G & 23 & $(0.001)$ & 35.78 & $(0.001)$ & 30.06 & $(0.001)$ & 7.29 & $(0.001)$ & 23.20 & $(0.001)$ & 8.61 & $(0.001)$ & 14.22 \\
\hline $\mathrm{G} \times \mathrm{E}$ & 69 & $(0.001)$ & 19.95 & $(0.001)$ & 20.70 & $(0.001)$ & 12.63 & $(0.001)$ & 11.43 & $(0.001)$ & 17.16 & $(0.001)$ & 17.84 \\
\hline$P C 1^{a}$ & 25 & $(0.001)$ & 52.95 & $(0.001)$ & 58.68 & $(0.001)$ & 83.48 & $(0.001)$ & 64.87 & $(0.001)$ & 66.01 & $(0.001)$ & 62.76 \\
\hline$P C 2^{a}$ & 23 & $(0.001)$ & 34.41 & $(0.001)$ & 34.77 & $(0.01)$ & 11.32 & $(0.05)$ & 28.72 & $(0.01)$ & 25.88 & $(0.01)$ & 27.03 \\
\hline$P C 3^{a}$ & 21 & & 12.64 & & 6.55 & & 5.20 & & 6.41 & & 8.11 & & 10.21 \\
\hline Error & 96 & & 10.57 & & 8.25 & & 2.39 & & 7.60 & & 7.84 & & 8.82 \\
\hline $\mathrm{H}^{2}$ & & 0.85 & & 0.84 & & 0.77 & & 0.84 & & 0.59 & & 0.70 & \\
\hline
\end{tabular}

Note. SOV, source of variation; df, degrees of freedom; E, environment; G, genotype; PC, principal component of G $\times$ E from AMMI model; DtH, days to heading; PLH, plant height; GY, grain yield; TKW, thousand kernel weights; HI, harvest index; Biom, biomass.

${ }^{a}$ Partitioning of the $\mathrm{G} \times \mathrm{E}$. 
Table 3. Analysis of variance for days to maturity (DtM), grain filling period (GFP), spike per $\mathrm{m}^{2}\left(\mathrm{Spk} / \mathrm{m}^{2}\right)$ and number of grain per spike ( $\mathrm{Gr} / \mathrm{spk})$ expressed as ratio of the total variance (\% var.), significance $(p)$, and broad sense heritability $\left(\mathrm{H}^{2}\right)$ at two sites during season 2015-16 along the Senegal River

\begin{tabular}{|c|c|c|c|c|c|c|c|c|c|c|c|c|c|c|c|c|c|}
\hline \multirow{3}{*}{ SOV } & \multirow{3}{*}{$\mathrm{df}$} & \multicolumn{8}{|c|}{ Fanaye 2015-16 (FAN16) } & \multicolumn{8}{|c|}{ Kaedi 2015-16 (KED16) } \\
\hline & & \multicolumn{2}{|c|}{ DtM } & \multicolumn{2}{|c|}{ GFP } & \multicolumn{2}{|c|}{$\mathrm{Spk} / \mathrm{m}^{2}$} & \multicolumn{2}{|c|}{$\mathrm{Gr} / \mathrm{spk}$} & \multicolumn{2}{|c|}{ DtM } & \multicolumn{2}{|c|}{ GFP } & \multicolumn{2}{|c|}{$\mathrm{Spk} / \mathrm{m}^{2}$} & \multicolumn{2}{|c|}{$\mathrm{Gr} / \mathrm{spk}$} \\
\hline & & $p$ & $\%$ var. & $p$ & $\%$ var. & $p$ & $\%$ var. & $p$ & $\%$ var. & $p$ & $\%$ var. & $p$ & $\%$ var. & $p$ & $\%$ var. & $p$ & $\%$ var. \\
\hline $\mathrm{G}$ & 23 & $(0.05)$ & 86 & & 81 & $(0.05)$ & 86 & $(0.01)$ & 89 & $(0.01)$ & 95 & & 77 & $(0.01)$ & 90 & $(0.01)$ & 94 \\
\hline Error & 96 & & 14 & & 19 & & 14 & & 11 & & 5 & & 23 & & 10 & & 6 \\
\hline $\mathrm{H}^{2}$ & & 0.54 & & 0.4 & & 0.55 & & 0.65 & & 0.82 & & 0.3 & & 0.66 & & 0.80 & \\
\hline
\end{tabular}

Note. SOV, source of variation; $\mathrm{df}$, degrees of freedom; G, genotype; DtM, days to maturity; GFP, grain filling period; Spk $/ \mathrm{m}^{2}$, number of spikes per meter square; $\mathrm{Gr} / \mathrm{spk}$, number of grain per spike.

\subsection{Grain Yield Related Traits}

The ANOVA for GY and TKW was significant $(p<0.01)$ for $\mathrm{E}, \mathrm{G}$, and their interaction $(\mathrm{G} \times \mathrm{E})$. The GY mean across four environments (FAN15, FAN16, KED15 and KED16) was 2,484 $\mathrm{kg} \mathrm{ha}^{-1}$ and the CV was $9.6 \%$, while it was 3,078 $\mathrm{kg} \mathrm{ha}^{-1}$ for the 'validation' trial in 2016-17 with a CV of $15.5 \%$. The E explained the largest part of the total variation (77.7\%), $\mathrm{G}$ accounted for $7.3 \%$, and $\mathrm{G} \times \mathrm{E}$ for $12.6 \%$ (Table 2 and Table A6.1). The broad sense heritability was estimated at 0.77 . The variation in GY among genotypes at each environment is presented in Figure 2, while their average performance across four environments is presented in Table 1. In FAN15, GY averaged 4,047 kg ha ${ }^{-1}$ and ranged from a minimum of 2,076 kg ha ${ }^{-1}$ to a maximum of 5,330 kg ha ${ }^{-1}$ for line 'Icamoram7'. In FAN16 average GY dropped by $60 \%$ to $1,633 \mathrm{~kg} \mathrm{ha}^{-1}$, ranging from 1,113 to $2,259 \mathrm{~kg} \mathrm{ha}^{-1}$. In KED15, the average GY was 2,492 kg ha ${ }^{-1}$, with a minimum of $1,748 \mathrm{~kg} \mathrm{ha}^{-1}$ and a maximum of $3,091 \mathrm{~kg} \mathrm{ha}^{-1}$ reached by the same top yielding line of FAN15 ('Icamoram7'). In KED16 the average GY was reduced by 29\% to $1,771 \mathrm{~kg} \mathrm{ha}^{-1}$. GY average in the "validation" trial was 2,871 $\mathrm{kg} \mathrm{ha}^{-1}$ at FAN17 and 3,286 kg ha ${ }^{-1}$ at KED17.

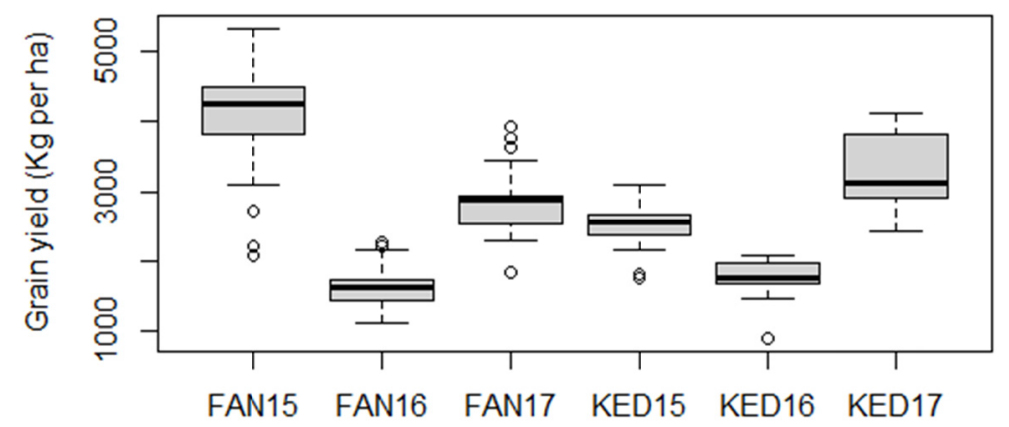

Figure 2. Grain yield distribution at two stations (KED-Kaedi, FAN-Fanaye) over seasons: 2014-15 (15), 2015-16(16) and 2016-17 (17). Thick dark horizontal lines show the averages, the box provides the total variation, whiskers have the length of one standard deviation, and empty circle indicate outliers

The combined analysis of genotypes performances across four environments (FAN15, FAN16, KED15, and KED16) identified 'Icamoram7', 'Margherita', 'Bani Suef 5', 'DAWRyT118', 'Icavert', 'DAWRyT123', 'DurAM-196' and 'DWAyT217' as the one third top yielders (Table 1), with performances from 6 to $18 \%$ above the grand mean. 'DAWRyT118' and 'DAWRyT123' were also $2^{\text {nd }}$ and $8^{\text {th }}$ top yielders of the 'validation' set with values non-significantly different than the top yielding line. Phenotypic variation was also identified for all other yield-related traits, and full details for each genotype at each site is provided as supplementary Dataset.

\subsection{Stability Analysis}

Combined ANOVA showed significance $(p<0.01)$ for $\mathrm{G} \times \mathrm{E}$ interaction for all agronomic traits. For $\mathrm{GY}, \mathrm{G} \times \mathrm{E}$ effect accounted for $12.6 \%$ of the total variance (Table 2) and was further partitioned by AMMI into three PCs, each explaining $83.5 \%, 11.3 \%$, and $5.2 \%$ of the $\mathrm{G} \times \mathrm{E}$ variation, respectively. The AWAI score was calculated, where a smaller value is indicative of genotypes falling closer to all PC axis and therefore more stable. Since $\mathrm{G} \times \mathrm{E}$ stability is also reached by genotypes that have low average yield performances, a selection index was designed to combine performances and stability in a bi-plot graph between the BLUE of GY and the AWAI 
(Figure 3). The top one third of the genotypes were selected from both axis. Two ICARDA elites ('DAWRyT118' and, 'DAWRyT123') and the Egyptian cultivar 'Bani Suef 5' were the top yielding and most stable performers along the Senegal River. The two ICARDA's elites were also confirmed as top yielders in the 'validation' set.

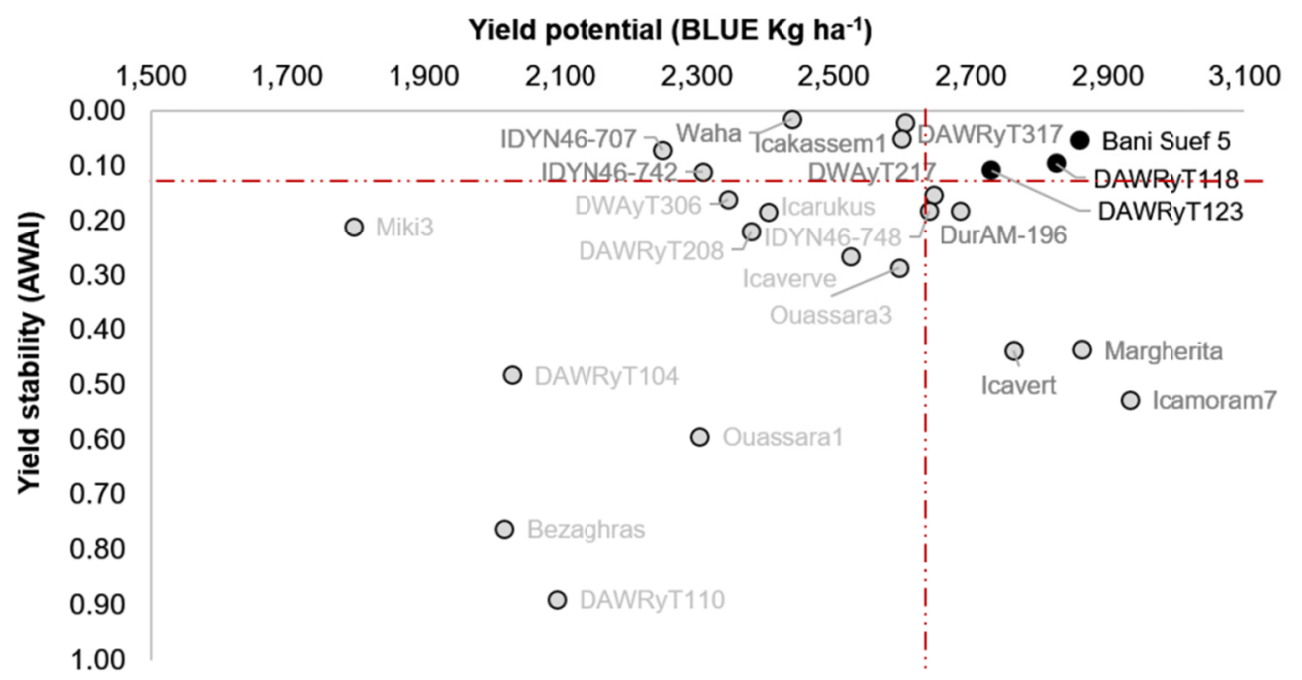

Figure 3. Biplot graph between the best linear unbiased estimator (BLUEs) for grain yield $\left(\mathrm{kg} \mathrm{ha}^{-1}\right)$ and the additive main effects multiplicative interaction (AMMI) model's wide adaptation index (AWAI). Dashed lines were placed in correspondence to $1 / 3$ best performing entry for each axis. The genotypes falling within the top right dashed square are the best yielding and most stable among those tested

\subsection{Interactions among Traits}

To understand the strategy utilized by the genotypes to adapt to the conditions of Senegal River Basin, a correlation matrix was developed to investigate associations between traits (Table 4). DtH was positively and highly correlated to DtM $(r=0.91, p<0.01)$. PLH affected positively TKW and Biom $(r=0.52, p<0.05$ and $r$ $=0.57, p<0.01$, respectively) and was negatively associated with $\mathrm{HI}(r=-0.52, p<0.05)$. The same negative association was observed between Biom and HI $(r=-0.44, p<0.05)$. Gr.spk and Biom were the only traits that affect positively GY $(r=0.48$ and $r=0.49$, respectively, $p<0.05)$.

Table 4. Matrix of correlations among traits combined across locations and years. Those underlined were either significant (underlined once) or highly significant (underlined twice)

\begin{tabular}{lllllllll}
\hline Traits & DtH & DtM & PLH & Spk $/ \mathrm{m}^{2}$ & Gr $/ \mathrm{spk}$ & TKW & Biom & GY \\
\hline DtM & $\underline{\underline{0.91}}$ & & & & & & & \\
PLH & 0.23 & -0.17 & & & & & & \\
Spk $/ \mathrm{m}^{2}$ & -0.23 & -0.25 & -0.13 & & & & & \\
Gr/spk & 0.34 & 0.35 & 0.09 & $\underline{\underline{\text { nv }}}$ & & & & \\
TKW & -0.19 & -0.19 & $\underline{\underline{0.52}}$ & -0.28 & -0.13 & & & \\
Biom & 0.35 & -0.25 & $\underline{\underline{0.57}}$ & 0.25 & 0.18 & -0.03 & & \\
GY & 0.02 & 0.13 & -0.02 & 0.27 & $\underline{0.48}$ & -0.17 & $\underline{0.49}$ & \\
HI & -0.23 & 0.37 & $\underline{\underline{-0.52}}$ & -0.04 & 0.28 & -0.22 & $\underline{-0.44}$ & 0.20
\end{tabular}

Note. Critical value Pearson's correlation for $23 \mathrm{df:} 0.53(\underline{p<0.01)}, 0.41(\underline{p<0.05})$. DtH, days to heading; DtM, days to maturity; PLH, plant height; Spk $/ \mathrm{m}^{2}$, spikes per $\mathrm{m}^{2}$; $\mathrm{Gr} / \mathrm{spk}$, grains per spike; TKW, 1,000, kernels weight; Biom, biomass; GY, grain yield; HI, harvest index; nv, not valid correlation.

A second analysis was conducted to further refine the identification of the traits used for adaptation. The top three (Top) and worst three (Worst) yielders at each location were singled out and compared for their performances across traits at each site (Table 5). The average GY was significantly different between the Top and 
Worst in all environments. Top and Worst genotypes had significant difference for $\mathrm{Gr} / \mathrm{spk}$ and Biom at two 'discovery' environment, and at one of the two 'validation' sites. PLH and HI showed significant differences only in one environment. All other traits had no significant differences between Top and Worst yielders during the two first seasons. Instead, in the 'validation' trials in 2016-17 DtH and DtM became significant at both sites.

Table 5. Top 3 and worst 3 yielding genotypes at each environment and comparison between their key traits for adaptation to heat stress

\begin{tabular}{|c|c|c|c|c|c|c|c|c|c|c|c|c|}
\hline \multirow{2}{*}{ Traits } & \multicolumn{4}{|c|}{ Fanaye 2014-15 } & \multicolumn{4}{|c|}{ Kaedi 2014-15 } & \multicolumn{4}{|c|}{ Fanaye 2015-16 } \\
\hline & LSD & Top & & Worst & LSD & Top & & Worst & LSD & Top & & Worst \\
\hline GY & 673 & 5,176 & $*$ & 2,337 & 383 & 2,934 & $*$ & 1,900 & 487 & 2,242 & $*$ & 1,116 \\
\hline DtH & 2 & 54 & & 52 & 2 & 51 & & 51 & 2 & 53 & & 52 \\
\hline DtM & . & . & & . & . & . & & . & 2 & 83 & & 81 \\
\hline PLH & 7 & 72 & & 76 & 5 & 63 & & 68 & 6 & 78 & & 75 \\
\hline $\mathrm{Spk} / \mathrm{m}^{2}$ & . & . & & . & . & . & & . & 63 & 352 & & 330 \\
\hline Gr/spk & . & . & & . & . & . & & . & 4 & 14 & $*$ & 8 \\
\hline TKW & 4 & 43 & & 44 & 3 & 34 & & 35 & 5 & 43 & & 44 \\
\hline Biom & 1,350 & 10,241 & $*$ & 8,422 & 969 & 7,405 & & 6,719 & 2,668 & 7,801 & & 6,179 \\
\hline HI & 7 & 51 & & 51 & 6 & 40 & $*$ & 31 & 12 & 28 & & 20 \\
\hline \multirow{2}{*}{ Traits } & \multicolumn{4}{|c|}{ Kaedi 2015-16 } & \multicolumn{4}{|c|}{ Fanaye 2016-17 } & \multicolumn{4}{|c|}{ Kaedi 2016-17 } \\
\hline & LSD & Top & & Worst & LSD & Top & & Worst & LSD & Top & & Worst \\
\hline GY & 415 & 2,069 & $*$ & 1,280 & 1,310 & 3,776 & $*$ & 2,179 & 529 & 4,080 & $*$ & 2,565 \\
\hline DtH & 3 & 51 & & 49 & 2 & 59 & $*$ & 63 & & 56 & $*$ & 52 \\
\hline DtM & 1 & 80 & & 80 & 3 & 89 & $*$ & 93 & 2 & 84 & * & 82 \\
\hline PLH & 5 & 65 & $*$ & 59 & 6 & 77 & & 76 & 8 & 68 & & 65 \\
\hline $\mathrm{Spk} / \mathrm{m}^{2}$ & 73 & 314 & & 252 & 114 & 325 & & 342 & 66 & 370 & & 319 \\
\hline Gr/spk & 3 & 19 & $*$ & 15 & 13 & 28 & & 19 & 7 & 33 & $*$ & 26 \\
\hline TKW & 2 & 35 & & 34 & 10 & 45 & & 37 & 4 & 34 & & 32 \\
\hline Biom & 1,395 & 6,189 & $*$ & 3,339 & 3,375 & 10,023 & & 7,884 & 1,539 & 9,188 & * & 6,374 \\
\hline HI & 8 & 35 & & 39 & 13 & 38 & & 27 & 7 & 45 & & 40 \\
\hline
\end{tabular}

Note. GY, grain yield; DtH, days to heading; DtM, days to maturity; PLH, plant height; Spk $/ \mathrm{m}^{2}$, spikes per $\mathrm{m}^{2}$; $\mathrm{Gr} / \mathrm{spk}$, grains per spike; TKW, 1,000, kernels weight; Biom, biomass; HI,harvest index. * More than one LSD significant difference between Top and Worst genotypes.

\section{Discussion}

\subsection{Two New Wheat Experimental Stations for Discriminating Heat Tolerance}

The stations of Fanaye, Senegal and Kaedi, Mauritania were selected to represent the agro-environmental diversity that occurs along the Senegal River, with a particular focus on the delta and middle valley, respectively. The E effect of the experiment captured $77.7 \%$ of the total variance for GY, suggesting that these two stations are adequately contrasting to conduct significant multi-locations breeding selection for heat tolerance (Figure C). The three seasons used for testing, 2014-15, 2015-16 and 2016-17 had clear differences in temperatures during the phase of flowering, mostly caused by the delay in sowing. In fact, GY at FAN16 and KED16 were $60 \%$ and $29 \%$ lower compared to the timely sown season 2014-15 at the same sites, respectively. In FAN16 the germplasm was exposed to the highest temperatures $\left(37^{\circ} \mathrm{C}\right)$ during the time of flowering time, which in turn caused a severe drop in productivity. The following season (FAN17) planting was further delayed, but a drop in temperature to $34^{\circ} \mathrm{C}$ occurred at the time of flowering, and this pushed the average GY to nearly double of what achieved in FAN16. This result shows the level of damage that the increase of just $3{ }^{\circ} \mathrm{C}$ in temperature can cause to the productivity of durum wheat if it occurs at the time of heading.

\subsection{Selecting the Most Heat Tolerant Genotypes}

The two stations over the two first seasons generated significant $(p<0.01) \mathrm{G} \times \mathrm{E}$ interaction for GY, indicating that the tested genotypes did not respond equally to the changes in temperatures and sowing time. However, several genotypes were found to be stable and high yielding regardless of these changes, such as 'DAWRyT118', 
'Bani Suef 5' and 'DAWRyT123'. These lines were among the top yielders in all environments and their AWAI score showed good stability (AWAI < 0.11). In particular, 'DAWRyT118' and 'DAWRyT123' were also confirmed as best performers in the 'validation' trials, which indicates that these lines carry heat tolerant traits capable of maintaining GY performance under stressed conditions. The two entries are in fact sister lines derived from top crossing the two most successful cultivars of the ICARDA durum program ('Om Rabi 5' and 'Cham 1') to Triticum dicoccoides collected in the surroundings of Aleppo (Table 1). Zaim et al. (2017) already described the usefulness of using $T$. dicoccoides in breeding durum elites, and identified 'DAWRYT118' as a top performer across drought prone sites in North Africa, with strong disease resistance, and good industrial processing qualities. Hence, their use in crossing schemes by durum breeders targeting heat tolerance is highly advised.

\subsection{Traits to be Targeted by Durum Wheat Breeders to Increase Tolerance to Heat Stress}

Heat stress has many detrimental effects on wheat at its various growth stages. Phenology traits (DtH and DtM) interacted among one another, but did not affect grain yield. Also, there was no significant difference between Top and Worst yielding lines for phenology in the two first season. Only the 'validation' set showed sufficient phenological variation to identified significant differences between Top and Worst. This would suggest that rather phenology is not an important characteristic for heat tolerance, when temperatures are constantly hot throughout the growing cycle as instead previously suggested by Hossain et al. (2012). Or more likely, the difference in results could be due to a limited amount of variation expressed for phenology by the 'discovery' set, while it was sufficient in the 'validation' set. Hence, phenology would instead represent a critical target that must be fixed through breeding first in order to then identify additional useful traits for heat tolerance.

High temperatures also shorten the tillering phase, resulting in poor setting of fertile tillers (Baldy, 1984). In addition, when heat occurs at the time of flowering it can reduce the vitality of the pollen and fertilization during pollen formation (Barlow et al., 2015; Draeger \& Moore, 2017). Instead, during the grain filling period, heat stress reduces grain size and its weight (Dias \& Lidon, 2009). Therefore, all these yield components appear of interest for improving heat tolerance. The number of $\mathrm{Gr} / \mathrm{spk}$ and Biom showed positive correlation to GY, and also scored as significantly different among Top and Worst genotypes in two 'discovery' and one 'validation' environments. This is in good agreement with previous research that has also shown that Biom plays a decisive role in favoring GY (Mekhlouf \& Bouzerzour, 2000; Abbassene et al., 1997; Masoni et al., 2007; Bahlouli et al., 2008). FAN16 was the environment with the most severe temperatures extremes during the flowering phase, and Gr/spk was identified as the only trait significantly different between Top and Worst elites at this location. Therefore, the ability of the best genotypes to maintain good fertilization under the severe heat resulted in better seed setting $(\mathrm{Gr} / \mathrm{spk})$ and ultimately higher yields. This is in agreement with Barnabas et al. (2008), and Hatfield and Prueger (2015), who found that the moment of fertilization is one of the most heat sensitive phase. Gr/spk represents therefore the single most appealing target trait for breeding better heat tolerance. The genotypes 'DAWRyT118' and 'DAWRyT123' were selected for their performances and stability. Their strategy for adaptation in fact relied mostly on the capacity of maintaining high spike fertility $(\mathrm{Gr} / \mathrm{spk})$ regardless of the temperatures, and to produce more Biom early in the cycle. Conversely, T. dicoccoides has been already praised by other authors for its capacity to produce vast biomass as well as for the fertility of its spikes (Merchuk-Ovnat et al., 2016a, 2016b; Merchuk-Ovnat et al., 2017). It is therefore not surprising that the two genotypes derived from it maintained these positive traits and used them to maximize heat tolerance.

\section{Conclusion}

The results presented here suggest that Senegal Valley provides ideal conditions for testing heat tolerance in wheat. A total of three genotypes identified as stable and well performing under these conditions ('DAWRyT118', 'DAWRyT123' and 'Bani Suef 5') showed good heat tolerance through the production of large biomass and maintenance of spike fertility. Breeders targeting improvement for this or similar regions should then focus on these traits, and possibly combining it with better harvest index. The Senegal River basin is regarded as a key place to bring social stability and food security to sub-Saharan Africa. Our results indicate that durum wheat is a suitable replacement of the fallow cycle and monoculture of rice. The area of possible expansion of wheat cultivation corresponds to the 200,000 ha currently grown as rice. Multiplying this area by the average yield of 3 $\mathrm{tha}^{-1}$ reached by the three best lines, suggests the potential of producing $600,000 \mathrm{t}$ of new food in sub-Saharan Africa, a potentially life-changing impact.

\section{Acknowledgements}

This research was financed by the Swedish Research Council (Vetenskapsradet) U-Forsk2013, "Deployment of molecular durum breeding to the Senegal Basin: capacity building to face global warming". The authors wish to thank the technical staff of CNRADA, ISRA, and ICARDA for support in conducting the field research. 


\section{References}

Abbassenne, F., Bouzerzour, H., \& Hachemi, L. (1997). Phénologie et production du blé dur (Triticum durum Desf.) en zone semi-aride. Annales Agronomiques Institut National Agronomique, 18, 24-36.

Alvarado, G., Lopez, M., Vargas, M., Pacheco, A., Rodriguez, F., Burgueno, J., \& Crossa, J. (2015). META-R (Multi Environment Trial Analysis with $R$ for Windows) (Version 5.0). CIMMYT, Mexico, D.F.

Ashraf, M., Quresh, A. S., Ghafoor, I. A., \& Khan, N. A. (2001). Genotype environment interaction in wheat. Journal of Biological Sciences, 1, 356-357. https://doi.org/10.3923/jbs.2001.356.357

Bado, V. B., Aw, A., \& Ndiaye, M. (2010). Long-term effect of continuous cropping of irrigated rice on soil and yield trends in the Sahel of West-Africa. Nutrient Cycling in Agroecosystems, 88, 133-141. https://doi.org/ $10.1007 / \mathrm{s} 10705-010-9355-7$

Bahlouli, F., Bouzerzour, H., \& Benmahammed, A. (2008). Effets de la vitesse et de la durée du remplissage du grain ainsi que de l'accumulation des assimilât de la tige dans l'élaboration du rendement du blé dur (Triticum durum Desf.) dans les conditions de culture des hautes plaines orientales d'Algérie. Biotechnology Agronomy Society and Environment, 12, 31-39.

Baldy, C. (1984). Agrométéorologie des cultures multiples en régions chaudes (p. 120). INRAF.

Bassi, F. M., \& Sanchez-Garcia, M. (2017). Adaptation and stability analysis of ICARDA durum wheat (Triticum durum Desf.) elites across 18 countries. Crop Science, 57, 1-12. https://doi.org/10.2135/cropsci2016. 11.0916

Barlow, K. M., Christy, B. P., O’Leary, G. J., Riffkin, P. A., \& Nuttall, J. G. (2015). Simulating the impact of extreme heat and frost events on wheat crop production: A review. Field Crops Research, 171, 109-119. https://doi.org/10.1016/j.fcr.2014.11.010

Barnabas, B., Jager, K., \& Feher, A. (2008). The effect of drought and heat stress on reproductive processes in cereals. Plant Cell Environment, 31, 11-38. https://doi.org/10.1111/j.1365-3040.2007.01727.x

Becker, H. C., \& Leon, J. (1988). Stability analysis in plant breeding. Plant Breeding, 101, 1-23. https://doi.org/10.1111/j.1439-0523.1988.tb00261.X

Boy, J., \& Wilcke, W. (2008). Tropical Andean forest derives calcium and magnesium from Saharan dust. Global Biogeochemical Cycles, 22, GB1027. https://doi.org/10.1029/2007GB002960

Burton, G. W., \& Devane, E. H. (1953). Estimation of heritability in tall Festuca (Festuca arudindcea) from replicated clonal material. Agronomy Journal, 45, 478-481. https://doi.org/10.2134/agronj1953.0002196200 $4500100005 \mathrm{x}$

Crossa, J. (1990). Statistical analysis of multilocation trials. Advances in Agronomy, 44, 55-85. https://doi.org/ 10.1016/S0065-2113(08)60818-4

Dias, A. S., \& Lidon, F. C. (2009). Evaluation of grain filling rate and duration in bread and durum wheat, under heat stress after anthesis. Journal of Agronomy and Crop Science, 195, 137-147. https://doi.org/10.1111/ j.1439-037X.2008.00347.x

Draeger, T., \& Moore, G. (2017). Short periods of high temperature during meiosis prevent normal meiotic progression and reduce grain number in hexaploid wheat (Triticum aestivum L.). Theor Appl Genet, 130, 1785-1800. https://doi.org/10.1007/s00122-017-2925-1

FAO (Food and Agricultural Organization). (2016). Senegal: Irrigation market brief (Report No. 26). Rome, Italy. Retrieved May 11, 2017, from http://www.fao.org/3/a-i5365e.pdf

Hatfield, J. L., \& Prueger, J. H. (2015). Temperature extremes: Effect on plant growth and development. Weather and Climate Extremes, 10, 4-10. https://doi.org/10.1016/j.wace.2015.08.001

Hossain, A., Teixeira da Silva, J. A., Lozovskaya, M. V., \& Zvolinsky, V. P. (2012). The effect of high temperature stress on the phenology, growth and yield of five wheat (Triticum aestivum L.) genotypes. Asian Australasian Journal of Plant Science and Biotechnology, 6, 14-23.

Lin, C. S, Binns, M. R., \& Lefkovitch, L. P. (1986). Stability analysis: Where do we stand? Crop Science, 26, 894-900. https://doi.org/10.2135/cropsci1986.0011183X002600050012x

Lin, C. S., \& Binns, M. R. (1994). Concepts and methods for analyzing regional trial data for cultivar and location selection. Plant Breeding Review, 12, 271-297. https://doi.org/10.2135/cropsci1986.0011183X0026 $00050012 x$ 
Malosetti, M., Ribaut, J., \& Van, E. F. A. (2013). The statistical analysis of multi-environment data: Modeling genotype-by-environment interaction and its genetic basis. Frontiers in Physiology, 4, 11-17. https://doi.org/10.3389/fphys.2013.00044

Masoni, A., Ercoli, L., Mariotti, M., \& Arduini, I. (2007). Post-anthesis accumulation and remobilization of dry matter, nitrogen and phosphorus in durum wheat as affected by soil type. European Journal of Agronomy, 26, 179-186. https://doi.org/10.1016/j.eja.2006.09.006

Merchuk-Ovnat, L., Fahima, T., Krugman, T., \& Saranga, Y. (2016a). Ancestral QTL alleles from wild emmer wheat improve grain yield, biomass and photosynthesis across environments in modern wheat. Plant Science, 251, 23-24. https://doi.org/10.1016/j.plantsci.2016.05.003

Merchuk-Ovnat, L., Barak, V., Fahima, T., Ordon, F., Lidzbarsky, G. A., Krugman, T., \& Saranga, Y. (2016b). Ancestral QTL alleles from wild emmer wheat improve drought resistance and productivity in modern wheat cultivars. Frontiers in Plant Science, 7, 452. https://dx.doi.org/10.3389\%2Ffpls.2016.00452

Merchuk-Ovnat, L., Fahima, T., Ephrath, J. E., Krugman, T., \& Saranga, Y. (2017). Ancestral QTL alleles from wild emmer wheat enhance root development under drought in modern wheat. Frontiers in Plant Science, 8 , 703. https://doi.org/10.3389\%2Ffpls.2017.00703

Mekhlouf, A., \& Bouzerzour, H. (2000). Déterminisme génétique et associations entre le rendement et quelques caractères à variation continue chez le blé dur (Triticum durum Desf.). Recherche Agronomique (INRAA), 7, 37-49.

Mohammadi, R., \& Amri, A. (2008). Comparison of parametric and non-parametric methods for selecting stable and adapted durum wheat genotypes in variable environments. Euphytica, 159, 419-432. https://doi.org/ 10.1007/s10681-007-9600-6

Najafian, G., Kaffashi, A. K., \& Jafar-Nezhad, A. (2010). Analysis of grain yield stability in hexaploid wheat genotypes grown in temperate regions of Iran using additive main effects and multiplicative interaction. Journal of Agricultural Science and Technology, 12, 213-222.

Pacheco, A., Vargas, M., Alvarado, G., Rodriguez, F., Lopez, M., Crossa, J., \& Burgueno, J. (2015). GEA-R (Genotype $\times$ Environment Analysis with R for Windows) (Version 2.0) .CIMMYT, Mexico, D.F.

R Core Team. (2015). R: A language and environment for statistical computing. R Foundation for Statistical Computing, Vienna, Austria. Retrieved from http://www.R-project.org

Yaghotipoor, A., \& Farshadfar, E. (2007). Non-parametric estimation and component analysis of phenotypic stability in chickpea (Cicer arietinum L.). Pakistan Journal of Biological Science, 10, 26-46. https://doi.org/10.3923/pjbs.2007.2646.2652

Zadoks, J. C., Chang, T. T., \& Konzak, C. F. (1974). A decimal code for growth stages of cereals. Weed Research, 14, 415-421. https://doi.org/10.1111/j.1365-3180.1974.tb01084.x

Zaim, M., El Hassounia, K., Gamba, F., Filali-Maltoufa, A., Belkadia, B., Sourour, A., ... Bassi, F. M. (2017). Wide crosses of durum wheat (Triticum durum Desf.) reveal good disease resistance, yield stability, and industrial quality across Mediterranean sites. Field Crop Research, 214, 219-227. https://oi.org/10.1016/ j.fcr.2017.09.007

Zali, H., Farshadfar, E., \& Sabaghpour, S. H. (2011). Non-parametric analysis of phenotypic stability in chickpea (Cicer arietinum L.) genotypes in Iran. Crop Breeding Journal, 1, 89-100.

Zobel, R. W., Wright, M. J., \& Gauch, H. G. (1988). Statistical analysis of a yield trial. Agronomy Journal, 80, 388-393. https://doi.org/10.2134/agronj1988.00021962008000030002x 


\section{Appendix}

Appendix A. ANOVA tables of all traits in all environments

Table A1. ANOVA tables of days to heading

Table A1.1. Combined ANOVA across four environments (FAN15, FAN16, KED15 and KED16)

\begin{tabular}{llllllll}
\hline SOV & SS & PORCENT & PORCENAC & df & MS & F & PROBF \\
\hline ENV & 393.80729 & 37.6851 & 37.6851 & 3 & 131.2691 & 102.03914 & 0 \\
GEN & 418.11979 & 40.01166 & 77.69676 & 23 & 18.17912 & 14.13114 & 0 \\
ENV $^{*}$ GEN & 233.06771 & 22.30324 & 100 & 69 & 3.37779 & 2.62565 & 0.00001 \\
PC1 & 124.78853 & 52.95196 & 52.95196 & 25 & 4.99154 & 4.28955 & 0 \\
PC2 & 81.08349 & 34.40644 & 87.3584 & 23 & 3.52537 & 3.02958 & 0.00047 \\
PC3 & 29.79165 & 12.6416 & 100 & 21 & 1.41865 & 1.21914 & 0.27522 \\
PC4 & 0 & 0 & 100 & 19 & 0 & 0 & 1 \\
Residuals & 123.5 & 0 & 0 & 96 & 1.28646 & NA & NA \\
\hline
\end{tabular}

Table A1.2. ANOVA of days to heading in FAN17

\begin{tabular}{llllll}
\hline SOV & df & Sum Sq & Mean Sq & F value & $\operatorname{Pr}(>\mathrm{F})$ \\
\hline Genotypes & 23 & 307.597 & 13.374 & 16.635 & $2.69 \mathrm{E}-06^{* * *}$ \\
Residuals & 13 & 10.451 & 0.804 & & \\
\hline
\end{tabular}

Table A1.3. ANOVA of days to heading in KED17

\begin{tabular}{llllll}
\hline SOV & df & Sum Sq & Mean Sq & F value & $\operatorname{Pr}(>\mathrm{F})$ \\
\hline Genotypes & 23 & 392.31 & 17.0571 & 30.324 & $6.86 \mathrm{E}-08^{* * *}$ \\
Residuals & 13 & 7.31 & 0.5625 & & \\
\hline
\end{tabular}

Table A2. ANOVA tables of plant height

Table A2.1. Combined ANOVA across four environments (FAN15, FAN16, KED15 and KED16)

\begin{tabular}{llllllll}
\hline SOV & SS & PORCENT & PORCENAC & df & MS & F & PROBF \\
\hline ENV & 4485.55729 & 44.68208 & 44.68208 & 3 & 1495.18576 & 159.04469 & 0 \\
GEN & 3288.45312 & 32.75734 & 77.43942 & 23 & 142.97622 & 15.20855 & 0 \\
ENV $^{*}$ GEN & 2264.81771 & 22.56058 & 100 & 69 & 32.82345 & 3.49147 & 0 \\
PC1 & 1363.46279 & 58.68321 & 58.68321 & 25 & 54.53851 & 7.77204 & 0 \\
PC2 & 807.84054 & 34.76932 & 93.45253 & 23 & 35.1235 & 5.00529 & 0 \\
PC3 & 152.12579 & 6.54747 & 100 & 21 & 7.24409 & 1.03232 & 0.44491 \\
PC4 & 0 & 0 & 100 & 19 & 0 & 0 & 1 \\
Residuals & 902.5 & 0 & 0 & 96 & 9.40104 & NA & NA \\
\hline
\end{tabular}

Table A2.2. ANOVA in FAN17

\begin{tabular}{llllll}
\hline SOV & df & Sum Sq & Mean Sq & F value & $\operatorname{Pr}(>\mathrm{F})$ \\
\hline Genotypes & 23 & 555.24 & 24.1407 & 3.0619 & $0.02015^{*}$ \\
Residuals & 13 & 102.5 & 7.8843 & & \\
\hline
\end{tabular}

Table A2.3. ANOVA in KED17

\begin{tabular}{llllll}
\hline SOV & df & Sum Sq & Mean Sq & F value & $\operatorname{Pr}(>\mathrm{F})$ \\
\hline Genotypes & 23 & 1144.21 & 49.748 & 4.9531 & $0.002244^{* *}$ \\
Residuals & 13 & 130.57 & 10.044 & & \\
\hline
\end{tabular}


Table A3. ANOVA tables of biomass

Table A3.1. Combined ANOVA across four environments (FAN15, FAN16, KED15 and KED16)

\begin{tabular}{llllllll}
\hline SOV & SS & PORCENT & PORCENAC & df & MS & F & PROBF \\
\hline ENV & 458010479 & 64.8325 & 64.8325 & 3 & 152670160 & 214.44405 & 0 \\
GEN & 110200240 & 15.59911 & 80.43161 & 23 & 4791314.78 & 6.72999 & 0 \\
ENV*GEN & 138241296 & 19.56839 & 100 & 69 & 2003497.05 & 2.81416 & 0 \\
PC1 & 83686108 & 62.75976 & 62.75976 & 25 & 3347444.32 & 5.64576 & 0 \\
PC2 & 36037580.5 & 27.02611 & 89.78588 & 23 & 1566851.32 & 2.64263 & 0.00189 \\
PC3 & 13619877.5 & 10.21412 & 100 & 21 & 648565.597 & 1.09386 & 0.38322 \\
PC4 & 0 & 0 & 100 & 19 & 0 & 0 & 1 \\
Residuals & 68345730.5 & 0 & 0 & 96 & 711934.693 & NA & NA \\
\hline
\end{tabular}

Table A3.2. ANOVA in FAN17

\begin{tabular}{llllll}
\hline SOV & df & Sum Sq & Mean Sq & F value & $\operatorname{Pr}(>\mathrm{F})$ \\
\hline Gnotypes & 23 & 54645387 & 2375886 & 1.4045 & 0.2661 \\
Residuals & 13 & 21991330 & 1691641 & & \\
\hline
\end{tabular}

Table A3.3. ANOVA in KED17

\begin{tabular}{llllll}
\hline SOV & df & Sum Sq & Mean Sq & F value & $\operatorname{Pr}(>\mathrm{F})$ \\
\hline Genotypes & 23 & 26443797 & 1149730 & 3.7886 & $0.007991^{* *}$ \\
Residuals & 13 & 3945148 & 303473 & & \\
\hline
\end{tabular}

Table A4. ANOVA tables of thousand kernel weight

Table A4.1. Combined ANOVA across four environments (FAN15, FAN16, KED15 and KED16)

\begin{tabular}{llllllll}
\hline SOV & SS & PORCENT & PORCENAC & df & MS & F & PROBF \\
\hline ENV & 2776.04167 & 62.51994 & 62.51994 & 3 & 925.34722 & 243.379 & 0 \\
GEN & 1114.75 & 25.10557 & 87.62551 & 23 & 48.46739 & 12.74759 & 0 \\
ENV $^{*}$ GEN & 549.45833 & 12.37449 & 100 & 69 & 7.96316 & 2.09442 & 0.00041 \\
PC1 & 353.32486 & 64.86914 & 64.86914 & 25 & 14.13299 & 3.91812 & 0.00002 \\
PC2 & 156.44081 & 28.72196 & 93.5911 & 23 & 6.80177 & 1.88567 & 0.0297 \\
PC3 & 34.90758 & 6.4089 & 100 & 21 & 1.66227 & 0.46084 & 0.97288 \\
PC4 & 0 & 0 & 100 & 19 & 0 & 0 & 1 \\
Residuals & 365 & 0 & 0 & 96 & 3.80208 & NA & NA \\
\hline
\end{tabular}

Table A4.2. ANOVA in FAN17

\begin{tabular}{llllll}
\hline SOV & df & Sum Sq & Mean Sq & F value & $\operatorname{Pr}(>$ F $)$ \\
\hline Genotypes & 23 & 472.9 & 20.561 & 1.0862 & 0.4523 \\
Residuals & 13 & 246.07 & 18.928 & & \\
\hline
\end{tabular}

Table A4.3. ANOVA in KED17

\begin{tabular}{llllll}
\hline SOV & df & Sum Sq & Mean Sq & F value & $\operatorname{Pr}(>\mathrm{F})$ \\
\hline Genotypes & 23 & 156.667 & 6.8116 & 1.7956 & 0.1373 \\
Residuals & 13 & 49.315 & 3.7935 & & \\
\hline
\end{tabular}


Table A5. ANOVA tables of harvest index

Table A5.1. Combined ANOVA across four environments (FAN15, FAN16, KED15 and KED16)

\begin{tabular}{llllllll}
\hline SOV & SS & PORCENT & PORCENAC & df & MS & F & PROBF \\
\hline ENV & 12408.6823 & 72.03777 & 72.03777 & 3 & 4136.22743 & 270.95042 & 0 \\
GEN & 1610.11979 & 9.34744 & 81.38521 & 23 & 70.00521 & 4.58581 & 0 \\
ENV*GEN & 3206.44271 & 18.61479 & 100 & 69 & 46.47018 & 3.04411 & 0 \\
PC1 & 2116.53764 & 66.00889 & 66.00889 & 25 & 84.66151 & 5.4112 & 0 \\
PC2 & 829.78342 & 25.87863 & 91.88752 & 23 & 36.07754 & 2.30592 & 0.00644 \\
PC3 & 260.12212 & 8.11248 & 100 & 21 & 12.38677 & 0.79171 & 0.71605 \\
PC4 & 0 & 0 & 100 & 19 & 0 & 0 & 1 \\
Residuals & 1465.5 & 0 & 0 & 96 & 15.26562 & NA & NA \\
\hline
\end{tabular}

Table A5.2. ANOVA in FAN17

\begin{tabular}{llllll}
\hline SOV & df & Sum Sq & Mean Sq & F value & $\operatorname{Pr}(>\mathrm{F})$ \\
\hline Genotypes & 23 & 2209.53 & 96.067 & 2.2609 & 0.06472 \\
Residuals & 13 & 552.37 & 42.49 & & \\
\hline
\end{tabular}

Table A5.3. ANOVA in KED17

\begin{tabular}{llllll}
\hline SOV & df & Sum Sq & Mean Sq & F value & $\operatorname{Pr}(>\mathrm{F})$ \\
\hline Genotypes & 23 & 581.73 & 25.2925 & 2.6473 & $0.03612^{*}$ \\
Residuals & 13 & 124.2 & 9.5542 & & \\
\hline
\end{tabular}

Table A6. ANOVA tables of grain yield

Table A6.1. Combined ANOVA across four environments (FAN15, FAN16, KED15 and KED16)

\begin{tabular}{llllllll}
\hline SOV & SS & PORCENT & PORCENAC & df & MS & F & PROBF \\
\hline ENV & 176873915 & 79.59798 & 79.59798 & 3 & 58957971.8 & 1040.00694 & 0 \\
GEN & 16591033.2 & 7.46641 & 87.06439 & 23 & 721349.271 & 12.72446 & 0 \\
ENV ${ }^{*}$ GEN & 28744097.4 & 12.93561 & 100 & 69 & 416581.121 & 7.34841 & 0 \\
PC1 & 23995126.1 & 83.47845 & 83.47845 & 25 & 959805.046 & 16.65322 & 0 \\
PC2 & 3254626.87 & 11.32277 & 94.80121 & 23 & 141505.516 & 2.45521 & 0.00373 \\
PC3 & 1494344.34 & 5.19879 & 100 & 21 & 71159.2541 & 1.23466 & 0.26358 \\
PC4 & 0 & 0 & 100 & 19 & 0 & 0 & 1 \\
Residuals & 5442238 & 0 & 0 & 96 & 56689.9792 & NA & NA \\
\hline
\end{tabular}

Table A6.2. ANOVA in FAN17

\begin{tabular}{llllll}
\hline SOV & df & Sum Sq & Mean Sq & F value & $\operatorname{Pr}(>\mathrm{F})$ \\
\hline Genotypes & 23 & 15604475 & 678455 & 3.661 & $0.009322^{* *}$ \\
Residuals & 13 & 2409163 & 185320 & & \\
\hline
\end{tabular}

Table A6.3. ANOVA in KED17

\begin{tabular}{llllll}
\hline SOV & df & Sum Sq & Mean Sq & F value & $\operatorname{Pr}(>\mathrm{F})$ \\
\hline Genotypes & 23 & 9307709 & 404683 & 8.4176 & $0.0001384 * * *$ \\
Residuals & 13 & 624988 & 48076 & & \\
\hline
\end{tabular}

Table A7. ANOVA tables of days to maturity

Table A7.1. ANOVA in KED16

\begin{tabular}{llllll}
\hline SOV & df & Sum Sq & Mean Sq & F value & $\operatorname{Pr}(>\mathrm{F})$ \\
\hline Genotypes & 23 & 98 & 4.2609 & 10.226 & $4.64 \mathrm{E}-05^{* * *}$ \\
Residuals & 13 & 624988 & 48076 & & \\
\hline
\end{tabular}


Table A7.2. ANOVA in KED17

\begin{tabular}{llllll}
\hline SOV & df & Sum Sq & Mean Sq & F value & $\operatorname{Pr}(>\mathrm{F})$ \\
\hline Genotypes & 23 & 392.31 & 17.0571 & 30.324 & $6.86 \mathrm{E}-08^{* * *}$ \\
Residuals & 13 & 7.31 & 0.5625 & & \\
\hline
\end{tabular}

Table A7.3. ANOVA in FAN16

\begin{tabular}{llllll}
\hline SOV & df & Sum Sq & Mean Sq & F value & $\operatorname{Pr}(>\mathrm{F})$ \\
\hline Genotypes & 23 & 97.323 & 4.2315 & 3.3357 & $0.01403^{*}$ \\
Residuals & 13 & 16.491 & 1.2685 & & \\
\hline
\end{tabular}

Table A7.4. ANOVA in FAN17

\begin{tabular}{llllll}
\hline SOV & df & Sum Sq & Mean Sq & F value & $\operatorname{Pr}(>\mathrm{F})$ \\
\hline Genotypes & 23 & 510.48 & 22.1947 & 9.2639 & $8.12 \mathrm{E}-05^{* * *}$ \\
Residuals & 13 & 31.15 & 2.3958 & & \\
\hline
\end{tabular}

Table A8. ANOVA tables of grain filling period

Table A8.1 ANOVA in KED16

\begin{tabular}{llllll}
\hline SOV & df & Sum Sq & Mean Sq & F value & $\operatorname{Pr}(>$ F $)$ \\
\hline Genotypes & 23 & 39.979 & 1.73822 & 1.9403 & 0.1081 \\
Residuals & 13 & 11.646 & 0.89583 & & \\
\hline
\end{tabular}

Table A8.2 ANOVA in FAN16

\begin{tabular}{llllll}
\hline SOV & df & Sum Sq & Mean Sq & F value & $\operatorname{Pr}(>\mathrm{F})$ \\
\hline Genotypes & 23 & 35.25 & 1.53261 & 2.35 & 0.05638 \\
Residuals & 13 & 8.478 & 0.65217 & & \\
\hline
\end{tabular}

Table A9. ANOVA tables of spikes per $\mathrm{m}^{2}$

Table A9.1. ANOVA in KED16

\begin{tabular}{llllll}
\hline SOV & df & Sum Sq & Mean Sq & F value & $\operatorname{Pr}(>\mathrm{F})$ \\
\hline Genotypes & 23 & 135662 & 5898.4 & 4.8826 & $0.002408^{* *}$ \\
Residuals & 13 & 15705 & 1208 & & \\
\hline
\end{tabular}

Table A9.2. ANOVA in KED 17

\begin{tabular}{llllll}
\hline SOV & df & Sum Sq & Mean Sq & F value & $\operatorname{Pr}(>\mathrm{F})$ \\
\hline Genotypes & 23 & 26360 & 1146.1 & 1.118 & 0.4298 \\
Residuals & 13 & 13327 & 1025.2 & & \\
\hline
\end{tabular}

Table A9.3. ANOVA in FAN16

\begin{tabular}{llllll}
\hline SOV & df & Sum Sq & Mean Sq & F value & $\operatorname{Pr}(>\mathrm{F})$ \\
\hline Genotypes & 23 & 71610 & 3113.49 & 3.4107 & $0.01274^{*}$ \\
Residuals & 13 & 11867 & 912.87 & & \\
\hline
\end{tabular}

Table A9.4. ANOVA in FAN17

\begin{tabular}{llllll}
\hline SOV & df & Sum Sq & Mean Sq & F value & $\operatorname{Pr}(>$ F $)$ \\
\hline Genotypes & 23 & 35327 & 1535.9 & 0.7023 & 0.7781 \\
Residuals & 13 & 28432 & 2187.1 & & \\
\hline
\end{tabular}


Table A10. ANOVA tables of grains per spike

Table A10.1. ANOVA in KED16

\begin{tabular}{llllll}
\hline SOV & df & Sum Sq & Mean Sq & F value & $\operatorname{Pr}(>\mathrm{F})$ \\
\hline Genotypes & 23 & 452.48 & 19.673 & 8.9934 & $9.58 \mathrm{E}-05^{* * *}$ \\
Residuals & 13 & 28.44 & 2.1875 & & \\
\hline
\end{tabular}

Table A10.2. ANOVA in KED17

\begin{tabular}{llllll}
\hline SOV & df & Sum Sq & Mean Sq & F value & $\operatorname{Pr}(>$ F $)$ \\
\hline Genotypes & 23 & 425.57 & 18.5031 & 1.8773 & 0.1199 \\
Residuals & 13 & 128.13 & 9.8564 & & \\
\hline
\end{tabular}

Table A10.3. ANOVA in FAN16

\begin{tabular}{llllll}
\hline SOV & df & Sum Sq & Mean Sq & F value & $\operatorname{Pr}(>\mathrm{F})$ \\
\hline Genotypes & 23 & 346.51 & 15.0656 & 4.7061 & $0.002883^{* *}$ \\
Residuals & 13 & 41.62 & 3.2013 & & \\
\hline
\end{tabular}

Table A10.4. ANOVA in FAN17

\begin{tabular}{llllll}
\hline SOV & df & Sum Sq & Mean Sq & F value & $\operatorname{Pr}(>$ F $)$ \\
\hline Genotypes & 23 & 961.19 & 41.791 & 2.1358 & 0.07883 \\
Residuals & 13 & 254.37 & 19.567 & & \\
\hline
\end{tabular}

Appendix B

Table B1. Durum wheat genotypes used for 'validation' trial, their best linear unbiased estimator (BLUE) for grain yield across two sites in season 2016-17and its summary statistics

\begin{tabular}{|c|c|c|c|}
\hline Genotypes & Pedigree & BLUE & \\
\hline AfN_14 & Korifla/AegSpeltoidesSyr//Loukos & 3,881 & a \\
\hline DAWRyT0118 & Mrb5/TdicoAlpCol//Cham1 & 3,559 & $a b$ \\
\hline AfN_19 & Younes/TdicoAlpCol//Korifla & 3,539 & $a b$ \\
\hline ADYT14_29 & IcamorTA041/4/IcamorTA0469/3/Bcr/Gro1//Mgnl1/5/MIKI2 & 3,514 & $a b c$ \\
\hline IDON38-38 & Terbol975/Geruftel2 = Margherita & 3,506 & $\mathrm{abc}$ \\
\hline AfN_05 & Korifla/AegSpeltoidesSyr//Amedakul & 3,387 & abcd \\
\hline IDON38-25 & CandocrossH25/BEZAIZAHF//Adnan2 & 3,356 & abcd \\
\hline DAWRyT0123 & Mrb5/TdicoAlpCol//Cham1 & 3,356 & abcd \\
\hline Ouassara3 & Ouasloukos1/5/Azn1/4/BEZAIZSHF//SD19539/ Waha/3/Gdr2 & 3,278 & abcde \\
\hline ADYT14_2 & Adnan1//Mgnl3/Ainzen1 & 3,239 & abcde \\
\hline ADYT14_55 & Oss11/Stj5/5/Bicrederaa1/4/BEZAIZSHF//SD19539/Waha/3/Stj/Mrb3/6/Stk/Hau//Heca1 & 3,222 & abcde \\
\hline IDON38-32 & Azeghar2/Murlagost2//Bicrederaa1/Azeghar2 & 3,067 & bcde \\
\hline ADYT14_27 & IcamorTA0471//IcamorTA0459/Arislahn10/3/Mgnl3/Ainzen1 & 2,983 & bcdef \\
\hline ADYT14_50 & Mgn13/Ainzen1/3/Bcr/Gro1//Mgnl1 & 2,878 & bcdef \\
\hline ADYT14_26 & IcamorTA0471//IcamorTA0459/Ammar8/4/Stj3//Dra2/Bcr/3/Ter3 & 2,832 & cdef \\
\hline IDON38-96 & Maamouri1/5/IcamorTA0462/4/Stj3//Bcr/Lks4/3/Icamors/6/Mgn13/Ainzen1 & 2,831 & cdef \\
\hline AfN_18 & Amedakul1/TdicoJCol//Cham1 & 2,823 & cdef \\
\hline IDON38-09 & Icamilmus1/Waha/4/Icasyr1/3/Bcr/Sbl5//Turartu & 2,781 & def \\
\hline Bani Suef 5 & Dupperez/Bushen3 & 2,739 & def \\
\hline ADYT14_58 & Azeghar1//Blrn/Mrf2/3/Bicrederaa1/Azeghar2 & 2,739 & def \\
\hline IDON38-42 & Bicrederaa1//Ossl1/Stj5/3/Ammar8 & 2,722 & def \\
\hline ADYT14_19 & $\begin{array}{l}\text { Mrb3/Tdicoccoides601116//IcamorTA0463/Zna4/4/Stj3//Bcr/Lks4/3/ } \\
\text { Ter3/6/Oss11/Stj5/5/Bicrederaa1/4/BezaizSHF//SD19539/Waha/3/Stj/Mrb3 }\end{array}$ & 2,690 & def \\
\hline ADYT14_73 & Ouasloukos1/5/Azn1/4/BEZAIZSHF//SD19539/Waha/3/Gdr2 & 2,646 & ef \\
\hline IDON38-49 & $\mathrm{Bcr} / \mathrm{Lks} 4 / / \mathrm{Mrf1} / \mathrm{Stj} 2 / 3 / \mathrm{Mrf} 2 /$ NormalHamari//Bcr/Lks4 & 2,311 & $\mathrm{f}$ \\
\hline Grand Mean & & 3,078 & \\
\hline LSD & & 698 & \\
\hline $\mathrm{CV}$ & & 16 & \\
\hline
\end{tabular}




\section{Appendix C}

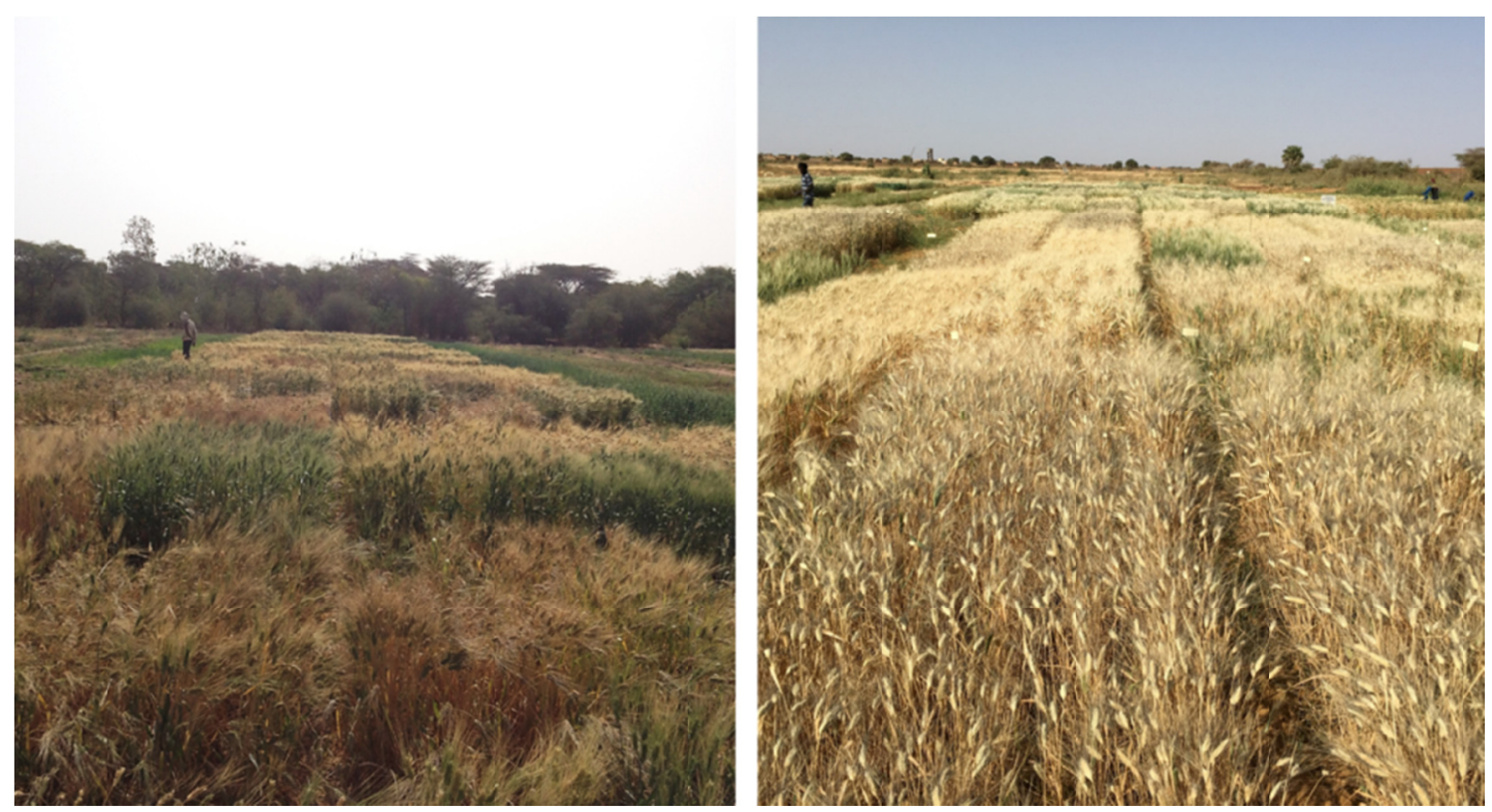

Figure C1. Experimental plots used for conducting yield trials in 2015/16, left Fanaye, Senegal and right Kaedi, Mauritania

\section{Copyrights}

Copyright for this article is retained by the author(s), with first publication rights granted to the journal.

This is an open-access article distributed under the terms and conditions of the Creative Commons Attribution license (http://creativecommons.org/licenses/by/4.0/). 